\title{
CRYSTAL GROWTH AND THE FORMATION OF SPIKES IN THE SURFACE OF SUPERGOOLED WATER
}

\author{
By J. Hallett \\ (Department of Meteorology, Imperial College, London)
}

\begin{abstract}
Observations made of ice crystals growing on the surface of supercooled water show that they take the form of a composite structure, called surface needles, each of which consists of dendrites growing into the liquid, and of ribs growing in the liquid surface. Each needle is a single crystal. The precise form of the needle is determined by the orientation of the initial nucleus. If its optic axis is near normal to the surface, growth occurs rapidly in two dimensions and covers a much larger proportion of the surface than is covered by the narrow surface needles, so that ice forming this way appears to have its optic axis vertical. Hollow ice spikes observed on pools are shown to have been formed by the freezing of water forced from beneath the surface at the intersection of two or three surface needles, the shape of the spike depending on their orientation.
\end{abstract}

RÉsumÉ. Des observations faites sur des cristaux de glace en train de se former à la surface d'eau surfondue. montrent que ces cristaux revêtent la forme d'une structure composite, dite "aiguille de surface", et que chacune de ces structures comprend des dendrites qui s'arborisent vers le bas, dans le liquide, et en même temps des arêtes qui s'étendent sur la surface. Chaque aiguille constitue un seul cristal. La forme précise de l'aiguille est déterminée par l'orientation du noyau originel. Si l'axe optique de l'aiguille est près de $90^{\circ}$ de la surface, la croissance se produit rapidement dans deux dimensions, et recouvre de glace une proportion plus considérable de la surface que ne le font les aiguilles de surface minces, de sorte que la glace qui se forme de cette manière semble avoir un axe optique vertical. On a constaté que les pointes creuses qu'on observe sur des étangs et sur des bassins d'eau se forment par la congélation d'eau forcée d'en dessous vers la surface juste au point d'intersection de deux ou trois aiguilles, et la forme précise de ces pointes est également commandée par l'orientation des aiguilies.

Zusammentassung. Beobachtungen an Eiskristallen, die auf der Oberfläche untergekühlten Wassers entstehen, zeigen, dass sie eine zusammengesetzte Struktur, die sogenannten Oberflächennadeln, aufweisen. Jede Nadel besteht aus Dendriten, die in das Wasser hineinragen, und aus auf der Oberfläche wachsenden Rippen. Jede Nadel stellt einen Einzelkristall dar. Die genaue Form der Nadel wird von der Orientierung des ursprünglichen Keimes bestimmt. Stcht seine optische Achse fast senkrecht zur Oberfläche, so wächst er rasch und zwei-dimensionell und nimmt einen viel grösseren Teil der Oberfläche ein als die schmalen Oberflächennadeln, so dass es den Anschein hat, dass die optische Achse des sich auf dieser Weise bildenden Eises senkrecht ist. Es wird gezeigt, dass auf Pfühlen beobachtete hohle Eisspiesse durch das Gefrieren des Wassers entstehen, das von unter der Oberfläche emporgetrieben wird, wo sich zwei oder drei Oberflächennadeln durchschneiden. Deren Orientierung bestimmt die Form des Spiesses.

\section{INTRODUCTION}

The freezing of liquid water is sometimes accompanied by the outward growth of long spikes of ice from its free surface. These have been observed to grow on the surface of puddles in the open air, and also on droplets greater than about I mm. in diameter., 2, 3 This investigation examines the mode of growth of ice crystals in the liquid surface and relates this to the occurrence and orientation of ice spikes.

\section{The Freezing of Water}

There is an extensive and somewhat conflicting literature on the mode of freezing of large volumes of water. References quoted by Dorsey ${ }^{\mathrm{I}}$ show that in general ice forms on water with its optic axis normal to the surface. Occasionally, however, the optic axis is found to occur parallel to the surface, especially when the water is considerably supercooled and the first ice crystals to form are of "needle" type. Extensive investigations of ice forms produced when slightly supercooled water is nucleated with ice crystals produced in the air above by a body cooled to $-50^{\circ} \mathrm{C}$. have been made by Arakawa and Higuchi, 4 Kumai and Itagaki 5 and Arakawa., 7 Their results show that crystals initially grow as thin discs or dendritic stars, depending on their size, concentration and the degree of supercooling of the water. The optic axes of these crystals are perpendicular to their plane which usually lies in the liquid surface. Should a disc crystal become inclined at an angle to the surface, growth takes place from each edge in the liquid surface, in the form of a long, thin, needle-like growth, which appears to be confined to the surface layer. 
The present author has made observations on the formation of ice on melt-water pools on the surface of a glacier and on water contained in open insulated trays in a cold laboratory. In each case the liquid is cooled at its top surface: the glacier pool radiates heat to a clear sky at night, and the water in the tray loses heat to cold air moving over its surface. It was found that initial growth always took place in the form of needle-like crystals, growing over the surface with a velocity of order $50 \mu /$ sec., with supercooling about $I^{\circ} \mathrm{C}$.

In previous work on ice crystals grown from the liquid, the term "needle" has been used for forms which appear in the surface as long, thin crystals. In order to avoid confusion with the needle crystal grown from the vapour ${ }^{8}$ where the $c$-axis is parallel to the long needle axis, the forms which occur in the liquid will be called "surface needles."

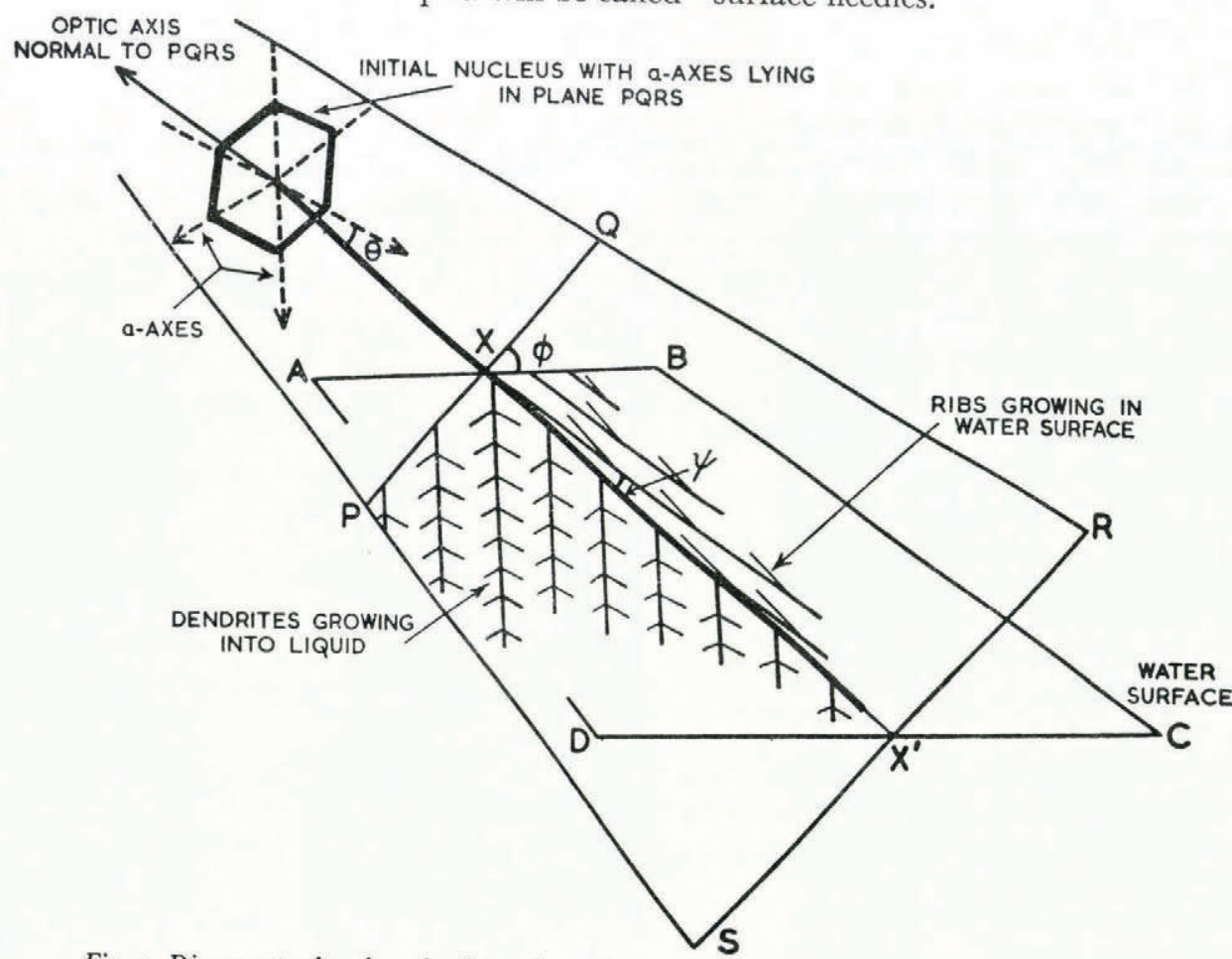

Fig. 2. Diagram to show how the slope of a surface needle is related to the orientation of the nucleus

The surface needle is characterized by asymmetric development on the two sides of its long axis. On one side lateral growth takes place in the surface as a series of parallel ribs (Fig. I (p. 703), upper). These ribs sometimes develop side growths which subsequently fill in to give a continuous sheet of ice, which is slightly thicker in the direction of the original ribs. On the other side (Fig. I, lower), flat dendrites (branched growths with arms at $60^{\circ}$ as occur in natural snow-flakes) grow downwards into the liquid, inclined at an angle which varies from specimen to specimen.

In general, the extent of the lateral growth is about roo times less than the growth along the needle axis. Examination of needles between crossed polaroids shows that each is a single crystal with its optic axis perpendicular to the plane of the dendrites. Two special cases can occur: with its optic axis perpendicular to the surface the crystal grows as a dendritic star, possessing hexagonal symmetry; with its optic axis parallel to the surface the crystal grows as a narrow, symmetrical needle with dendrites growing vertically downwards into the liquid. Figures 2 and 3 show how the orientations of dendrites and ribs are related to that of 
the initial nucleus. The angle which the ribs make with the direction of growth $(\psi)$ is related to the angle which the basal plane makes with the surface $(\phi)$, and the direction of the $a$-axis nearest to the direction of needle growth $(\theta)$ by $\tan \psi=\tan \theta \cos \phi$. The ribs lie along a direction which is a projection of an $a$-axis of the basal plane of the initial nucleus, on the liquid surface. It follows that, when the optic axis is vertical, ribs become identical with dendrites.

The observations show that, for a particular supercooling, growth occurs much more rapidly (about Ioo times) parallel to the basal plane of ice. The shape of any particular ice crystal will therefore reflect the interplay of these different growth rates and the processes of heat transfer, by convection and conduction in the liquid around the crystal, which will be influenced by the distribution of the supercooling in the liquid. Since the entire surface layer of water is supercooled in the cases examined, the surface needles will grow until they either meet other needles, or the walls of the container or pool. The reason for the asymmetry of the needle is that the latent heat evolved by the growth of the dendrites into the liquid prevents large supercooling in the water immediately above, so that growth on this side of the needle is significantly reduced.

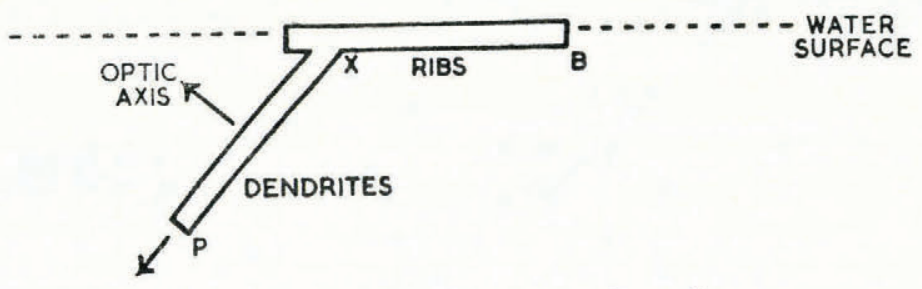

Fig. 3. Section PXB through the surface needle

It was noted earlier that ice growing on the surface of water usually has its optic axis vertical. This follows from a consideration of the relative growth rates of crystals at various orientations in the surface. Those crystals with optic axes farther than a few degrees from the vertical will grow as narrow needles with lateral growth rate significantly less than that along the needle axis. Dendrites growing into the liquid will do so as far as the depth of the supercooled layer permits, but dendrites growing in the surface, i.e. with optic axes nearly perpendicular to the surface, will grow rapidly in two dimensions and will cover a much greater area of the surface than the narrow needles.

The orientations of the initial crystal nuclei have not yet been considered. In the case of a glacier pool, these will be ice crystals in the side wall, which will generally have an arbitrary orientation, as also will nuclei present in the water. If the freezing nuclei are snow crystals falling from the atmosphere, then these may fall and float with a preferred orientation, depending on their shape ${ }^{8}$ (hexagonal prisms with optic axis horizontal, and hexagonal plates with optic axis vertical), and give rise to this orientation when they subsequently grow in the liquid.

\section{The Formation of Ice Spikes}

It has been shown by Blanchard ${ }^{2}$ and Mason and Maybank 3 that spikes are produced by a freezing droplet when it is nucleated near $\mathrm{o}^{\circ} \mathrm{C}$. First ice spreads slowly across the droplet surface. The spike then forms by the expulsion of water from a "point of weakness" in the surface. Some information on the formation of these spikes has been obtained by observation of spikes produced during the freezing of melt-water pools on a glacier. Typical spikes are shown in Figures 4, 5 and 6 (p. 703-04). Invariably a spike is produced at the intersection of two surface needles whose optic axes are nearly horizontal. This is clearly shown by the ice section in Figure 7 (p. 704). This section was cut from the surface of a pool, through the base of a 
spike, melted by contact with a warm metal plate to a few millimetres thickness and examined between crossed polaroids. Where the optic axis is normal to the ice section (and the photograph in Figure 7), the crystal is in an extinction position which is the dark background. The spike emerged from the corner between the needles, which have their optic axes at about $10^{\circ}$ to the horizontal. The spike consisted of three separate crystals, each with a distinct orientation (Fig. 8). The spike grows as the water is pushed upwards from below the surface by the expansion caused by ice formation. Water freezes at the edge of the surface needles with the orientation of the needle, and so a spike is gradually built up as more and more water is expelled. Possible sites for the formation of spikes can be seen by looking at the reflection of a light in the surface of a pool. They appear as triangular patches of water, which on close investigation are found to have two or sometimes three needles as their periphery, with dendrites growing almost vertically downwards into the liquid. A long spike is most likely to be produced from that hole which remains after all others have frozen over. The length of a spike will therefore be determined by its width and the amount of water available from below the surface, before the spike becomes frozen solid, or has its water supply cut off by crystal growth from below. The angle which the spikes make with the surface will depend on the initial orientation of the needles, growth taking place preferentially parallel to the basal plane. A spike growing from three needles with optic axes nearly horizontal, for example, will possess three almost vertical plane sides. This is shown in Figures 5 and 6 (p. 703-04), where the plane faces of the spike are normal to the optic axes. The direction of the optic axes in this case was found from the orientations of Tyndall flowers, internal melt figures, formed by the preferential absorbtion of solar radiation at motes incorporated in the ice. The third edge of this spike (which had almost melted when the photograph was taken) was not bounded by a plane face, as would be expected, because its optic axis was almost vertical.

Supercooled droplets which occur in clouds in the atmosphere can freeze by a number of mechanisms. The droplet may contain freezing nuclei which are active below a particular temperature, or if the temperature is sufficiently low, nuclei may form spontaneously.

As soon as freezing begins the temperature of the drop rises to near $0^{\circ} \mathrm{C}$. by the release of latent heat, no further nuclei will be brought into action and the droplet will freeze as a single crystal. It is difficult to predict the initial mode of growth, as there is no experimental work available on the nature of crystal growth in deeply supercooled water. It would appear. that once the temperature has risen to near $0^{\circ} \mathrm{C}$., the drop will freeze from the outside, a shell growing from the ice which formed on the initial nucleus. A spike will form as this shell begins to seal. Explosive disruption can thus occur should the tip of the spike freeze and allow pressure to build up inside the drop.

It has been found by Mason and Maybank 3 that spike formation and disintegration of droplets only occurs when the supercooling is not too great. Deeply supercooled water contains much air in solution, which is released in the form of small bubbles as the temperature rises, preventing the internal pressures becoming sufficiently high to shatter the drop.

Alternatively the drop can be infected by small ice crystals carried down from a colder part of the cloud. Freezing can now begin from a number of points simultaneously, and a spike be produced as described above for a plane surface, to be followed by explosive shatter, if the spike freezes. Another possibility is that the drop can be caught by an ice particle already present, e.g. a graupel particle, when its mode of freezing will depend on the crystal structure of the substrate.

The photographs of ice spikes were taken whilst the author was taking part in the Gornergletscher Glaciological Survey.

MS. received 29 December 1959 


\section{REFERENCES}

I. Dorsey, N. E. Properties of ordinary water-substance. New York, Reinhold, r940, p. 409, 637.

2. Blanchard, P. C. A verification of the Bally-Dorsey theory of spicule formation on sleet pellets. Fournal of Meleorology, Vol. 8, 1951, p. 268-69.

3. Mason, B. J., and Maybank, J. The fragmentation and electrification of freezing water droplets. Quarterly Fournal of the Royal Meteorological Society, Vol. 86, No. 368, 1960, p. I76-86.

4. Arakawa, K., and Higuchi, K. Studies on the freezing of water. 1. Journal of the Faculty of Science, Hokkaidô University, Ser. 2, Vol. 4, No. 3, 1952, p. $201-08$.

5. Kumai, M., and Itagaki, K. Cinematographic study of ice crystal formation in water. Journal of the Faculty of Science, Hokkaido University, Ser. 2, Vol. 4, No. 4, 1953, p. 235-46.

6. Arakawa, K. Studies on the freezing of water. 2. Fournal of the Faculty of Science, Hokkaido University, Ser. 2, Vol. 4, No. 5, 1954, p. 311-39.

7. Arakawa, K. Studies on the freezing of water. 3. Fournal of the Faculty of Science, Hokkaido University, Ser. 2, Vol. 4, No. 6, 1955, p. 355-57.

8. Hallett, J., and Mason, B. J. The influence of temperature and supersaturation on the habit of ice crystals grown from the vapour. Proceedings of the Royal Society, Ser. A, Vol. 247, No. 1251, 1958, p. 440-53. 
Fig. I. Part of a surface needle showing dendrites with hexagonal symmetry, which were growing into the liquid at an angle of about $70^{\circ}$ to the surface. The ribs, which are growing on the surface, are visible in the upper part of the photograph
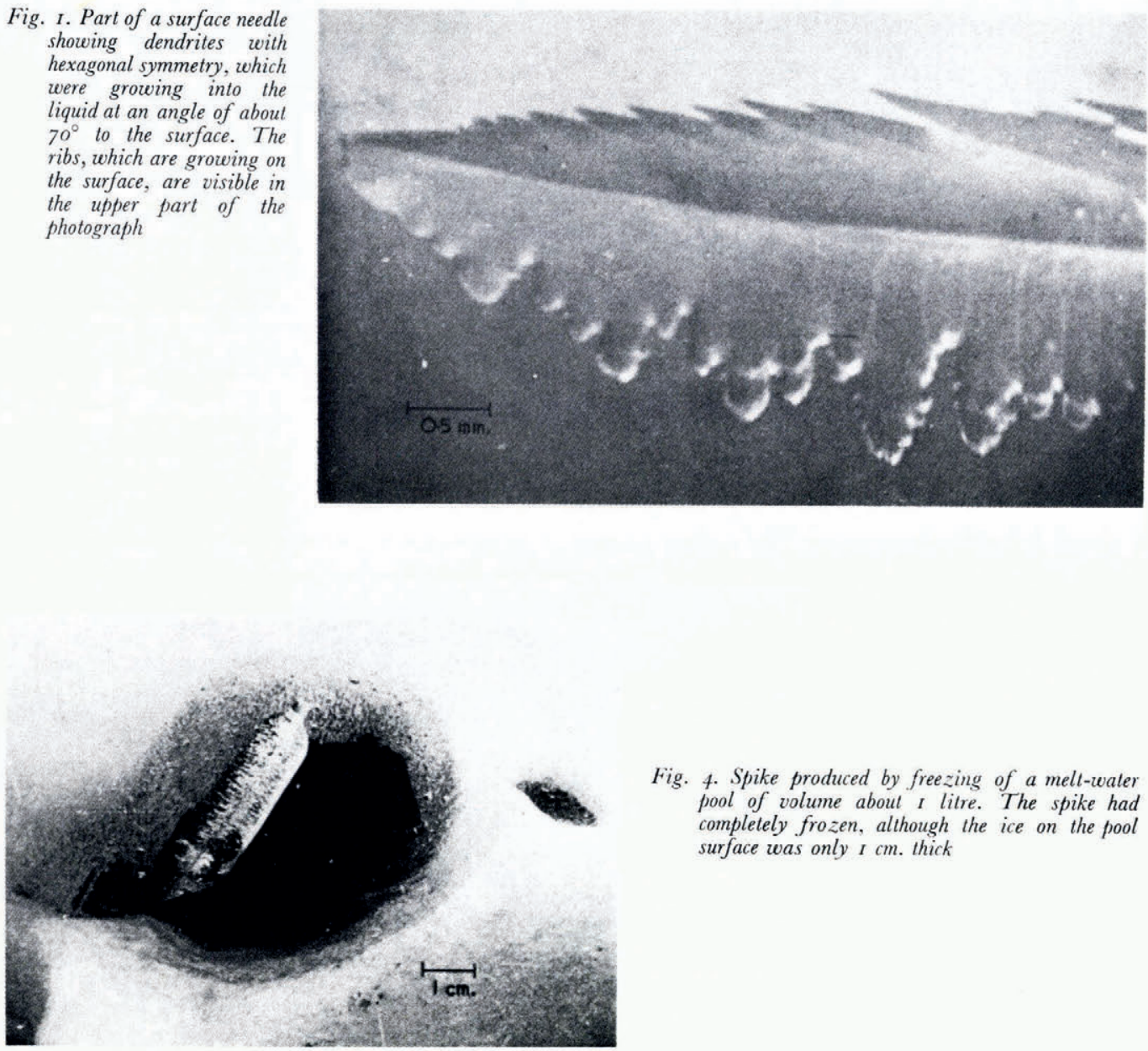

Fig. 4. Spike produced by freezing of a melt-water pool of volume about $I$ litre. The spike had completely frozen, although the ice on the pool surface was only $I \mathrm{~cm}$. thick

Fig. 5. A hollow spike, $10 \mathrm{~cm}$. in length, produced by the freezing of a large melt-water pool, volume Ioo litres. One side had partly melted when this photograph was taken

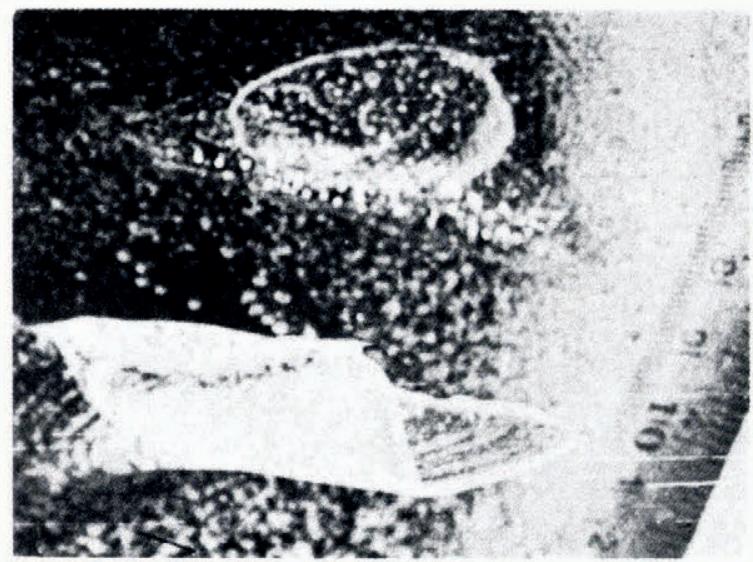




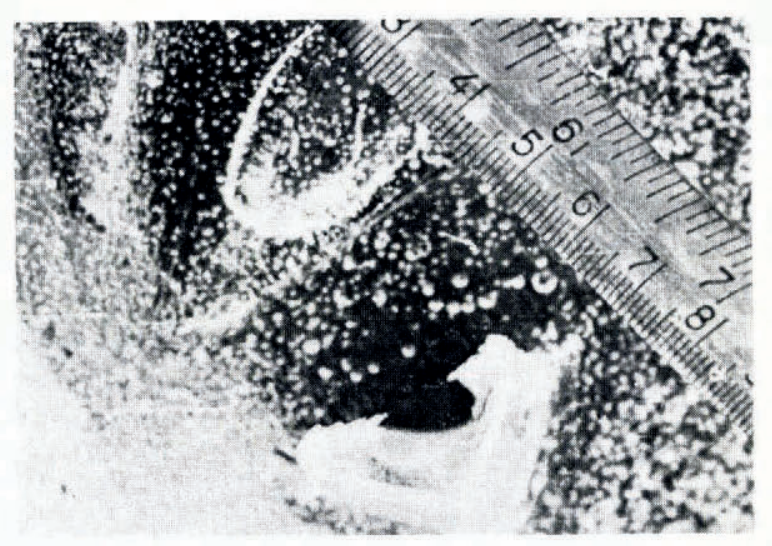

Fig. 6. View down the hollow spike shown in Figure 5

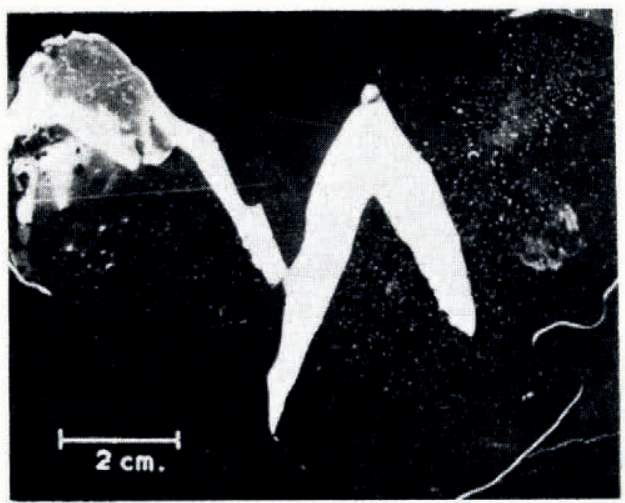

Fig. 7. A section through the base of a spike examined under crossed polaroids

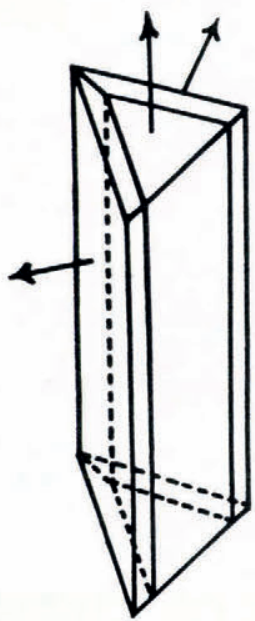

Fig. 8. Crystal structure of a spike. The arrows show the direction of the optic axis of each crystai 